\title{
Artikel
}

\section{Geen verhaalsrecht werkgever voor afgedragen pensioenpremie}

\author{
Mr. R.J. Schellevis*
}

\section{Inleiding}

Als een werknemer arbeidsongeschikt raakt, is de werkgever op grond van artikel 7:629 lid $1 \mathrm{BW}$, en vaak ook op grond van de geldende arbeidsovereenkomst, verplicht om het loon in ieder geval gedurende twee jaar (deels) door te betalen aan de arbeidsongeschikte werknemer. Deze kosten kunnen behoorlijk oplopen, maar de werkgever hoeft deze kosten niet altijd geheel zelf te dragen. In de gevallen waarin een derde aansprakelijk is voor de arbeidsongeschiktheid van de werknemer, kan de werkgever deze loonschade namelijk op grond van artikel 6:107a lid 2 BW op deze ansprakelijke derde verhalen.

De werkgever kan echter niet al zijn kosten bij arbeidsongeschiktheid van zijn werknemer verhalen. Uit de wetsgeschiedenis en de jurisprudentie van de Hoge Raad volgt namelijk dat het verhaalsrecht van de werkgever is beperkt tot de nettoloonkosten. Afgedragen loonbelasting en sociale premies vallen dus buiten het verhaalsrecht van de werkgever. Hoewel vanuit sommige hoeken kritiek is gekomen op dit netto-verhaalsrecht, bestaat hierover in de jurisprudentie geen verdeeldheid. Het gerechtshof Den Haag zag in 2018 toch reden om over de reikwijdte van dit verhaalsrecht prejudiciële vragen aan de Hoge Raad te stellen. ${ }^{1}$

Het gerechtshof heeft aan de Hoge Raad de vraag voorgelegd of onder het nettoloonbegrip ook de pensioenpremie valt die een werkgever verplicht heeft afgedra-

* Mr. R.J. Schellevis is werkzaam als advocaat bij KBS Advocaten te Utrecht.

1. Hof Den Haag 26 februari 2019, ECLI:NL:GHDHA:2019:340. gen tijdens de arbeidsongeschiktheid van een werknemer en of voor deze afgedragen premie dus regres kan worden genomen op de aansprakelijke partij. De Hoge Raad heeft zich op 15 november 2019 over deze vraag uitgelaten en kwam met een duidelijk - en mijns inziens een enigszins voorspelbaar - antwoord. ${ }^{2}$

\section{Het verhaalsrecht van de werkgever}

\subsection{De loondoorbetalingsplicht}

Voordat wordt toegekomen aan de bespreking van de beslissing van de Hoge Raad, wordt omwille van de begrijpelijkheid daarvan eerst stilgestaan bij het verhaalsrecht van de werkgever.

Al sinds 1909 heeft een arbeidsongeschikte werknemer op grond van artikel 1638c (oud) BW voor 'een betrekkelijk korten tijd' recht op loon. Dit werd echter lange tijd niet door de werkgever, maar door de overheid gefinancierd. Tot 1994 kon de arbeidsongeschikte werknemer namelijk een beroep doen op de Ziektewet, op grond waarvan hij gedurende 52 weken aanspraak had op een Ziektewetuitkering van $70 \%$ van het dagloon. Omdat de werkgever deze uitkering mocht verrekenen met het door hem door te betalen loon, had de werkgever enkel de plicht om deze uitkering aan te vullen. ${ }^{3}$ De wetgever heeft per 1 januari 1994 met de Wet Terugdringing Ziekteverzuim verandering in dit systeem aangebracht. Voortaan was de werkgever verplicht

2. HR 15 november 2019, ECLI:NL:HR:2019:1784

3. Overigens was artikel 1638 c (oud) BW van regelend recht en kon de werkgever de loondoorbetalingsplicht bij ziekte eenvoudig ter zijde stellen. 
om over de eerste zes (of bij kleine werkgevers twee) weken van het ziekteverzuim $70 \%$ van het loon aan de zieke werknemer door te betalen. Ruim twee jaar later is deze verantwoordelijkheid van de werkgever verder uitgebreid en werd deze periode met de Wet Uitbreiding Loondoorbetaling bij ziekte uitgebreid naar 52 weken en per 2004 is deze periode naar de huidige 104 weken verhoogd.

Het financiële risico van arbeidsongeschiktheid wegens ziekte is dus verschoven van de overheid naar de werkgever. De aanleiding van deze verschuiving was het in Nederland alsmaar toenemende percentage ziekteverzuim, wat als een zorgwekkend maatschappelijk probleem werd gezien. Volgens de wetgever zou door een vergroting van de financiële betrokkenheid van werkgevers en werknemers het ziekteverzuim omlaag worden gebracht. Enerzijds zou een vergroting van de financiële betrokkenheid volgens de regering aan de kant van de werkgevers leiden tot een grotere aandacht voor de kosten van het verzuim en daardoor tot een intensivering van het verzuimpreventiebeleid. Anderzijds zou een vergroting van de financiële betrokkenheid van de individuele werknemer ook leiden tot een grotere aandacht voor (de kosten van) het verzuim en om die reden van invloed zijn op de hoogte van de verzuimdrempel. ${ }^{4}$

\subsection{De reikwijdte van het verhaalsrecht}

Omdat het financiële risico van arbeidsongeschiktheid werd verplaatst van de overheid naar de werkgever, vond de wetgever het passend een verhaalsrecht voor de werkgever in het leven te roepen. Dit verhaalsrecht is neergelegd in artikel 6:107a BW. In lid 1 is bepaald dat bij de vaststelling van de schadevergoeding waarop de werknemer jegens de aansprakelijke derde aanspraak kan maken, rekening moet worden gehouden met de eventuele verplichting van de werkgever om het loon door te betalen. In dat geval verplaatst de schade naar de werkgever. Door deze verplichte voordeelstoerekening in de zin van artikel 6:100 BW wordt voorkomen dat de arbeidsongeschikte werknemer zowel van de aansprakelijke persoon als van zijn werkgever met succes vergoeding van dezelfde schade zou kunnen vorderen.

Lid 2 van artikel 6:107a BW bevat het verhaalsrecht van de werkgever op de aansprakelijke derde:

'Indien een werkgever krachtens artikel 629, lid 1, van Boek 7 of krachtens individuele of collectieve arbeidsovereenkomst verplicht is tijdens ziekte of arbeidsongeschiktheid van de gekwetste het loon door te betalen, heeft hij, indien de ongeschiktheid tot werken van de gekwetste het gevolg is van een gebeurtenis waarvoor een ander aansprakelijk is, jegens deze ander recht op schadevergoeding ten bedrage van de door hem betaalde loon, doch ten hoogste tot het bedrag, waarvoor de aansprakelijke persoon, bij het ontbreken van de loondoorbetalingsverplichting aansprakelijk zou zijn, verminderd met een bedrag, gelijk aan dat van de schadevergoeding

4. Kamerstukken I/ 1992/93, 22899, nr. 3, p. 19 tot betaling waarvan de aansprakelijke persoon jegens de gekwetste is gehouden.'

Met dit verhaalsrecht wordt voorkomen dat de aansprakelijke partij wegens het bepaalde in het eerste lid profiteert van het feit dat het slachtoffer zijn loon krijgt doorbetaald. Het verhaalsrecht is wel op drie manieren begrensd. Uit de wettekst van artikel 6:107a lid 2 BW volgt in de eerste plaats dat het verhaalsrecht is beperkt tot het loon dat de werkgever krachtens artikel 7:629 lid $1 \mathrm{BW}$ verschuldigd is, eventueel uitgebreid met een loondoorbetalingsplicht krachtens arbeidsovereenkomst of cao.

Het Burgerlijk Wetboek bevat geen definitie van het begrip 'loon'. Over de vraag wat in civiele zin onder het begrip loon moet worden verstaan, bestaat echter geen discussie. De Hoge Raad heeft in 1953 namelijk overwogen dat als loon in civiele zin moet worden beschouwd 'de vergoeding door den werkgever aan den werknemer verschuldigd ter zake van den bedongen arbeid $^{5}$ en heeft dit in een later arrest bevestigd. ${ }^{6}$

Uit artikel 7:629 BW volgt dat de werkgever verplicht is om slechts $70 \%$ van het loon door te betalen, maar dit percentage wordt in de arbeidsovereenkomst of de cao veelvuldig aangevuld tot 100 . Deze loondoorbetalingsplicht geldt op grond van artikel 7:629 BW in ieder geval gedurende 104 weken (of zoveel korter als de arbeidsovereenkomst duurt).

Ten tweede is het verhaalsrecht begrensd door het zogeheten 'civiel plafond'. Dit houdt in dat de werkgever alleen aanspraak kan maken op vergoeding van de kosten die de werknemer zelf zou hebben kunnen vorderen als geen sprake zou zijn geweest van verplaatsing van die schade. Ook deze begrenzing volgt uit de wettekst van artikel 6:107a lid $2 \mathrm{BW}$. De reden voor het invoeren van het civiel plafond is dat het verhaalsrecht van de werkgever er niet toe mag leiden dat de aansprakelijke partij in een slechtere positie raakt doordat de werkgever in plaats van de werknemer de schade vordert.

Tot slot is het verhaalsrecht beperkt tot het nettoloon. Dit betekent dat de werkgever enkel het bedrag kan verhalen dat de werknemer tijdens zijn arbeidsongeschiktheid op zijn bankrekening krijgt bijgeschreven. Deze begrenzing volgt niet uit de wettekst, maar uit de parlementaire geschiedenis en de jurisprudentie van de Hoge Raad. ${ }^{7}$

De gedachte achter deze begrenzing is dat de Hoge Raad in zijn jurisprudentie die ziet op het verhaalsrecht uit de socialeverzekeringswetten, heeft overwogen dat een door de werknemer gevorderde schadevergoeding doorgaans als bedrag ineens zal worden uitbetaald en dat over deze schadevergoeding dus geen belasting en sociale premies hoeven te worden afgedragen. Als zijn loon niet door de werkgever was doorbetaald, zou de

HR 18 december 1953, NJ 1954, 242.

HR 12 oktober 2001, JAR 2001/217 (Huize Bethesda).

Zie Kamerstukken II 1994/95, 24326, nr. 3, p. 48 en Kamerstukken II 1994/95, 24326, nr. 7, p. 7-8. Zie ook HR 13 december, NJ 1986, 246; HR 27 november 1987, NJ 1989, 48 en HR 25 februari 1994, NJ 1995, 608. 
werknemer dus aanspraak hebben gehad op (de contante waarde van) het nettoloon dat hij dan zou hebben gemist, aldus de Hoge Raad. ${ }^{8}$

In de memorie van toelichting bij artikel $6: 107 \mathrm{a} \mathrm{BW}$ is aansluiting gezocht bij deze jurisprudentie en is door de wetgever bevestigd dat de werkgever bij de uitoefening van zijn regresrecht slechts aanspraak zal kunnen maken op het netto door hem doorbetaalde loon. ${ }^{9}$ De wetgever heeft hierbij erkend dat het netto-verhaalsrecht tot gevolg heeft dat de werkgever niet al zijn kosten bij arbeidsongeschiktheid kan verhalen. ${ }^{10}$ Maar het uitgangspunt van het schadevergoedingsrecht dat een aansprakelijke partij niet meer dan de volledige schade behoeft te vergoeden, dient volgens de wetgever te prevaleren boven het belang van de werkgever. ${ }^{11}$ Daarnaast zou een verruiming van het verhaalsrecht tot het brutoloon ertoe leiden dat er een 'niet te rechtvaardigen' verschil ontstaat tussen de verschillende regresnemers. Ook het UWV en de Staat kunnen immers slechts de netto-uitkering of het nettoloon verhalen op de aansprakelijke derde. $^{12}$

In 2003 heeft de Hoge Raad bevestigd dat het in artikel 6:107a lid 2 BW neergelegde verhaalsrecht van de werkgever is beperkt tot de nettoloonkosten, en in 2004 is door hem overwogen dat de beperking tot het nettoloon ook geldt voor de bepaling van het civiele plafond. ${ }^{13}$

\section{De pensioenregeling kort uitgelegd}

Uit het voorgaande volgt dat het verhaalsrecht van de werkgever is beperkt tot de waarde van het nettoloon dat de werkgever op grond van artikel 7:629 lid 1 BW aan de arbeidsongeschikte werknemer tijdens zijn ziekte verschuldigd is. De vraag waar de Hoge Raad zich in de prejudiciële beslissing over heeft uitgelaten, is of de pensioenpremie die door een werkgever verplicht is afgedragen tijdens arbeidsongeschiktheid van een werknemer, onder voorgenoemd loonbegrip en dus onder het verhaalsrecht van de werkgever valt. Om de overwegingen van de Hoge Raad te begrijpen, is het van belang om eerst de verschillende verhoudingen binnen de pensioenregeling kort toe te lichten.

Op pensioenterrein is sprake van de zogenoemde 'pensioendriehoek': de driepartijenverhouding die ontstaat tussen werknemer, werkgever en pensioenuitvoerder

8. HR 13 december 1985, NJ 1986, 246 en HR 27 november 1987, NJ 1989,48

9. Kamerstukken II 1994/95, 24326, nr. 3, p. 48 en Kamerstukken I $1995 / 96,24326$, nr. 119b, p. 2.

10. Kamerstukken II 1994/95, 24326, nr. 7, p. 7-8 en Kamerstukken I 1995/96, 24326, nr. 119b, p. 2.

11. Kamerstukken II 1994/95, 24326, nr. 7, p. 7-8 en Kamerstukken I 1995/96, 24326, nr. 119b, p. 2. Zie ook Kamerstukken /l 2005/06, 30034, nr. 77, p. 3

12. Kamerstukken // 2005/06, 30034, nr. 77, p. 3

13. HR 24 oktober 2003, NJ 2004, 396 en HR 13 februari 2004, ECLI:NL:HR:2004:AN8600. door het sluiten en uitvoeren van een pensioenovereenkomst.

In de eerste plaats is er de verhouding tussen de werkgever en de werknemer, die is vastgelegd in de pensioenovereenkomst. Dit vormt de basis van de driehoeksverhouding. In de pensioenovereenkomst maken de werknemer en de werkgever afspraken over bijvoorbeeld de soort pensioenregeling en een eventuele bijdrage van de werknemer in de kosten van de pensioenopbouw. De tweede verhouding is die tussen de werkgever en de pensioenuitvoerder. De werkgever heeft de plicht om de voor pensioen bestemde gelden onder te brengen bij een pensioenuitvoerder en sluit hiertoe een uitvoeringsovereenkomst met de pensioenuitvoerder. Tot slot komt door het sluiten van die uitvoeringsovereenkomst een zelfstandige verhouding tussen de werknemer en de pensioenuitvoerder tot stand.

Voor het opbouwen van pensioen dient pensioenpremie betaald te worden. De merkgever dient de verschuldigde pensioenpremie aan de pensioenuitvoerder te voldoen; de werknemer is niet gehouden om premie aan de pensioenuitvoerder te betalen. Toch wordt soms onderscheid gemaakt tussen een werkgevers- en een werknemersdeel van de pensioenpremie.

De werkgever en werknemer kunnen namelijk onderling afspreken dat de werknemer bijdraagt aan de kosten van de pensioenregeling. De werknemer betaalt dit gedeelte niet rechtstreeks aan de pensioenuitvoerder, maar dit zogeheten 'werknemersgedeelte' van de pensioenpremie wordt door de werkgever ingehouden op het brutoloon van de werknemer. Er is voor gekozen om de werknemersbijdrage op het brutoloon in te houden omdat de werknemer anders dubbel belasting zou betalen: eerst over de pensioenpremie en later over de ontvangen pensioenuitkering.

Met het 'werkgeversgedeelte' van de pensioenpremie wordt de pensioenpremie minus de werknemerspremie bedoeld.

\section{Aanleiding voor het stellen van de prejudiciële vragen}

$\mathrm{Nu}$ de voor de beslissing van de Hoge Raad relevante leerstukken uiteen zijn gezet, wordt toegekomen aan de bespreking van de beslissing zelf. De achtergrond van de zaak die heeft geleid tot de beslissing, is als volgt.

Op 28 november 2007 heeft een verkeersongeval plaatsgevonden tussen een werknemer van een overslagbedrijf, Steinweg B.V., en een verzekerde van HDIGerling Verzekeringen N.V. Als gevolg van dit ongeval is de werknemer arbeidsongeschikt geraakt. Steinweg heeft het loon gedurende de eerste periode van het ziekteverzuim aan de werknemer doorbetaald en heeft voor deze loonschade verhaal gezocht op HDI. HDI heeft aansprakelijkheid erkend en de nettoloonschade van Steinweg aan Steinweg betaald. 
Steinweg heeft gedurende het ziekteverzuim van haar werknemer ook zijn pensioenpremie doorbetaald en wilde ook deze kosten verhalen op HDI. In 2015 heeft Steinweg HDI gedagvaard en, na vermeerdering van eis, onder andere gevorderd om HDI te veroordelen om de pensioenpremie die Steinweg gedurende de arbeidsongeschiktheid van haar werknemer heeft afgedragen, aan haar te betalen. Bij vonnis van 29 april 2016 heeft de rechtbank de vordering wat betreft de pensioenpremie afgewezen.

Steinweg is vervolgens van dit vonnis in hoger beroep gekomen. Het hof heeft toen, gelet op de onduidelijkheid die volgens het hof bestaat over de reikwijdte van het verhaalsrecht van de werkgever als bedoeld in artikel 6:107a lid 2 BW, aanleiding gezien de volgende prejudiciële vragen aan de Hoge Raad te stellen:

- Valt de pensioenpremie die door een werkgever verplicht doorbetaald/afgedragen is tijdens ziekte of arbeidsongeschiktheid van een werknemer onder het loonbegrip van artikel 6:107a BW?

- Indien uit het antwoord op de eerste vraag voortvloeit dat er een verhaalsrecht is voor de in deze zaak aan de orde zijnde pensioenpremie, bestaat er dan reden om een verschil te maken tussen het werknemersgedeelte en het werkgeversgedeelte van de betaalde/afgedragen pensioenpremie?

\section{Valt de pensioenpremie onder het verhaalsrecht van de werkgever?}

Aan de Hoge Raad lag dus de vraag voor of de pensioenpremie die door een werkgever verplicht is afgedragen tijdens arbeidsongeschiktheid van een werknemer, onder het verhaalsrecht van de werkgever valt. De Hoge Raad begint in zijn beslissing met het herhalen van de definitie van het civiele loonbegrip, namelijk 'de vergoeding die de werkgever voor de bedongen arbeid is verschuldigd aan de werknemer'. ${ }^{14}$ Dan makt de Hoge Raad een onderscheid tussen het werkgevers- en het werknemersgedeelte van de pensioenpremie.

Wat betreft het werkgeversgedeelte is de Hoge Raad zeer kort. Hij overweegt dat de werkgever dit deel niet inhoudt op de vergoeding die hij voor de bedongen arbeid is verschuldigd aan de werknemer, en dat het werkgeversgedeelte van de pensioenpremie om deze reden niet onder het loonbegrip van artikel 6:107a $\mathrm{BW}$ valt. Verhaal voor het werkgeversgedeelte van de pensioenpremie is dus niet mogelijk, aldus de Hoge Raad. ${ }^{15}$

Wat betreft het werknemersgedeelte overweegt de Hoge Raad dat de werkgever dit gedeelte van de pensioenpremie mel inhoudt op de vergoeding die hij voor de bedongen arbeid aan de werknemer verschuldigd is. Daarmee behoort het werknemersgedeelte van de pensioenpremie

14. HR 15 november 2019, ECLI:NL:HR:2019:1784, r.o. 2.8

15. HR 15 november 2019, ECLI:NL:HR:2019:1784, r.o. 2.8. wel tot het loon in de zin van artikel 6:107a BW, aldus de Hoge Raad. ${ }^{16}$

Dan overweegt de Hoge Raad dat het verhaalsrecht van de werkgever van artikel 6:107a lid $2 \mathrm{BW}$ beperkt is tot het nettoloon. De Hoge Raad stelt vast dat de werkgever de gehele pensioenpremie aan de pensioenuitvoerder is verschuldigd en dat hij slechts het werknemersgedeelte van de premie op het brutoloon kan inhouden. In de fictieve situatie dat de werkgever het loon niet aan de arbeidsongeschikte werknemer zou doorbetalen, omvat de schade van de werknemer die de aansprakelijke persoon aan hem moet vergoeden dan ook niet het werknemersgedeelte van de pensioenpremie. Volgens de Hoge Raad ligt het daarom voor de hand om artikel 6:107a lid 2 BW zo uit te leggen dat de werkgever ook geen verhaalsrecht heeft voor het op het loon ingehouden werknemersgedeelte van de pensioenpremie. ${ }^{17}$

Het antwoord op de eerste prejudiciële vraag luidt daarom dat het werknemersgedeelte van de pensioenpremie die de werkgever verplicht heeft afgedragen tijdens ziekte of arbeidsongeschiktheid van een werknemer, valt onder het loonbegrip van artikel 6:107a BW. Het werkgeversgedeelte van de pensioenpremie valt niet onder dit loonbegrip.

Het antwoord op de tweede vraag luidt dat artikel 6:107a lid 2 BW zo moet worden uitgelegd dat de werkgever geen verhaalsrecht heeft voor het werknemersgedeelte van de pensioenpremie. Verhaal voor het werkgeversgedeelte van de pensioenpremie is alleen al daarom niet mogelijk omdat dit gedeelte van de pensioenpremie niet valt onder het loonbegrip van artikel 6:107a BW.

\section{Beschouwing}

Hoewel de Hoge Raad zich nog niet eerder had uitgelaten over de vraag of afgedragen pensioenpremies onder het verhaalsrecht van de werkgever vallen, komt het ontkennende antwoord op deze vraag - gezien de wettekst, parlementaire geschiedenis en literatuur - mijns inziens niet als een verassing.

In de literatuur is de heersende opvatting (ook voordat deze beslissing was gegeven) namelijk dat het werkgeversgedeelte van de pensioenpremie niet te kwalificeren is als loon. ${ }^{18}$ Alleen al op basis hiervan ligt het voor de hand dat het werkgeversgedeelte van de pensioenpremie niet onder het verhaalsrecht van de werkgever valt.

Dat de Hoge Raad heeft geoordeeld dat ook het werknemersgedeelte van de pensioenpremie niet onder het verhaalsrecht van de werkgever valt, kan naar mijn mening evenmin worden bestempeld als een verassing. Immers, uit de parlementaire geschiedenis en de eerdere jurisprudentie van de Hoge Raad volgt ondubbelzinnig dat het verhaalsrecht van de werkgever is beperkt tot het nettoloon. Omdat het werknemersgedeelte van de door

\footnotetext{
16. HR 15 november 2019, ECLI:NL:HR:2019:1784, r.o. 2.8.

17. HR 15 november 2019, ECLI:NL:HR:2019:1784, r.o. 2.12.

18. Zie bijvoorbeeld Asser/Heerma van Voss 7-V 2015/95; Asser/Lutjens 7 XI 2016/390 en Van Slooten, a.w., p. 86.
} 
de werkgever af te dragen pensioenpremie wordt ingehouden op het brutoloon, is het - gelet op deze begrenzing - evident dat ook dit deel buiten het verhaalsrecht van de werkgever valt.

Waarom het gerechtshof dan toch reden zag om hierover prejudiciële vragen te stellen, is mij niet duidelijk. De overweging van het gerechtshof dat de vraag of afgedragen pensioenpremies onder het verhaalsrecht vallen in de rechtspraktijk 'op verschillende mijzen mordt beantpoord', komt immers niet in de wetsgeschiedenis, relevante rechtspraak of literatuur naar voren. ${ }^{19}$ A-G Drijber heeft zich dat in de conclusie bij de beslissing ook afgevraagd. Hij acht het mogelijk dat het gerechtshof mogelijk iets voelde voor het door de werkgever verdedigde standpunt, mede in het licht van de kritiek die in de literatuur naar voren is gekomen over de keuze van de wetgever voor het netto-verhaalsrecht. ${ }^{20}$

Wat daar ook van zij, feit is dat de wetgever bemust heeft gekozen voor het netto-verhaalsrecht. Hij heeft de nadelen die hieraan zijn verbonden onderkend, maar heeft uitdrukkelijk overwogen dat deze niet opwegen tegen het nut en de voordelen van het netto-verhaalsrecht. ${ }^{21}$ In de jurisprudentie van de Hoge Raad is dan ook altijd uitgegaan van verhaal van nettoloon. Er valt niet in te zien waarom dat anders zou zijn voor de afgedragen pensioenpremies. $^{22}$

\section{Ten slotte}

Hoewel van een baanbrekende beslissing geen sprake is, is de beslissing naar mijn mening wel van belang voor de rechtspraktijk. Aangezien de Hoge Raad in 2004 voor het laatst heeft bevestigd dat het verhaalsrecht van de werkgever van artikel 6:107a lid $2 \mathrm{BW}$ is beperkt tot het nettoloon en hier sindsdien vanuit de literatuur kritiek op is gekomen, is het goed dat de Hoge Raad (en ook A-G Drijber in zijn conclusie) het bestaan en belang van het netto-verhaalsrecht nog eens heeft benadrukt. Daarnaast kunnen met deze uitspraak onnodige procedures tussen een werkgever van een arbeidsongeschikte werknemer en de voor deze arbeidsongeschiktheid verantwoordelijke partij worden voorkomen, wat weer kan leiden tot een efficiëntere schadeafwikkeling. In die zin kan mijns inziens daarom toch worden geconcludeerd dat het voor de rechtspraktijk van belang is geweest dat het gerechtshof zich genoodzaakt heeft gezien om de

19. Zie ook de conclusie bij de beslissing: A-G Drijber, ECLI:NL:PHR: 2019:773, bij HR 15 november 2019, ECLI:NL:HR:2019:1784.

20. Zie bijvoorbeeld A.T. Bolt, GS Schadevergoeding, commentaar op art. 107a Boek 6 BW, aant. 8 en J.W.M. Tromp, Handboek Personenschade, nr. 4150.16. Hoewel er in de literatuur kritiek is geuit op deze keuze, krijgt de wetgever ook bijval. Zie bijvoorbeeld W.W.Y. Cheng, 'De reikwijdte van het regresrecht van de werkgever ex art. 6:107a BW', TAP 2012/8, p. 381-382.

21. Kamerstukken I/ 1994/95, 24326, nr. 7, p. 7-8 en Kamerstukken I $1995 / 96,24326$, nr. 119b, p. 2. Zie ook Kamerstukken I/ 2005/06, 30034, nr. 77, p. 3

22. Zie ook A-G Drijber, ECLI:NL:PHR:2019:773, bij HR 15 november 2019 ECLI:NL:HR:2019:1784. (wellicht overbodige) prejudiciële vragen aan de Hoge Raad te stellen. 